NBER WORKING PAPER SERIES

\title{
DOWNSIZING AND PRODUCTIVITY \\ GROWTH: MYTH OR REALITY?
}

Martin Neil Baily

Eric J. Bartelsman

John Haltiwanger

Working Paper No. 4741

\section{NATIONAL BUREAU OF ECONOMIC RESEARCH 1050 Massachusetts Avenue Cambridge, MA 02138 \\ May 1994}

The views expressed herein are solely the authors' and do not necessarily reflect those of the Board of Governors of the Federal Reserve System, its staff, or the National Bureau of Economic Research. We wish to thank the staff and visiting researchers at the Center for Economic Studies, U.S. Bureau of the Census, for providing a stimulating research environment. We would also like to thank participants of the NBER Summer '93 workshop for valuable comments and suggestions. This paper is part of NBER's research programs in Economic Fluctuations and Productivity. 


\title{
DOWNSIZING AND PRODUCTTVITY \\ GROWTH: MYTH OR REALITY?
}

\begin{abstract}
The conventional wisdom is that the rising productivity in the U.S. manufacturing sector in the 1980s has been driven by the apparently pervasive downsizing over this period. Aggregate evidence clearly shows falling employment accompanying the rise in productivity. In this paper, we examine the microeconomic evidence using the plant level data from the Longitudinal Research Database (LRD). In contrast to the conventional wisdom, we find that plants that increased employment as well as productivity contribute almost as much to overall productivity growth in the 1980 s as the plants that increased productivity at the expense of employment. Further, there are striking differences by sector (defined by industry, size, region, wages, and ownership type) in the allocation of plants in terms of whether they upsize or downsize and whether they increase or decrease productivity. Nevertheless, in spite of the striking differences across sectors defined in a variety of ways, most of the variance of productivity and employment growth is accounted for by idiosyncratic factors.
\end{abstract}

\author{
Martin Neil Baily \\ Department of Economics \\ University of Maryland \\ College Park, MD 20742 \\ and NBER \\ John Haltiwanger \\ Department of Economics \\ University of Maryland \\ College Park, MD 20742 \\ and NBER
}

\section{Eric J. Bartelsman}

Division of Research and Statistics Mail Stop 82

Federal Reserve Board

Washington, D.C. 20551 


\section{INTRODUCTION}

P'roductivity growth in the manufacturing sector of the U.S. economy has been rapid over the past decade, and has been accompanied by a substantial reduction in employment. This has engendered the conventional belief that rising productivity in manufacturing and decreasing employment are inextricably linked through some micro-economic mechanisms. Some hold the vicw that technological progress leads to layoffs because of mismatches between newly desired labor quality and the skills of existing workers, or because of rigidities in wages and prices (for a recent review, see Johnson (1994)). Others hold the alternative view that productivity growth happens as a result of downsizing, or re-engineering, with its concomitant layoffs. Large scale employment reductions by major companies are routinely reported in the media as part of this downsizing trend, and applauded by market analysts for improving productivity and making the company "lean and mean." The expansion of international trade is often seen as a source of the competitive pressure that has lead to downsizing.

The conventional wisdom that productivity growth and downsizing are connected has some basis in fact. Figure la depicts annual output and employment for the period 1958-89 for the total manufacturing sector and Figure $1 \mathrm{~b}$ depicts the annual grou:th rate in labor productivity over this time. During the 1960s and 1970s, output and employment fluctuated cyclically around a growing trend with modest growth in productivity. In the 1980 s, the pattern changed with output recovering robustly from the recession in the early 1980s and employment never fully recovering. Consequently. average labor productivity rose sharply over much of this period. We focus on this period of rising productivity and falling employment using plant level data for the Census of Manufactures in $197 \mathrm{i}$ and 1987. Over this interval, total employment in manufact uring establishments fell by 4.5 percent over the period 1977 to 1987 even as productivity (measured by value added per worker) rose by 33 percent. ${ }^{1}$ Thus, it would appear that our sample of plant level data is consistent with the conventional wisdom.

\footnotetext{
'Manufacturing employment as we describe it here is based upon the Censuses and Surveys of Manufacturing Establishments. Household surveys show that manufacturing employment has been pretty much flat over the last twenty years, barring cyclical downturns. The difference in the conclusions arises because R\&D and head office employees based on so-called "auxiliary establishments" are not included in the establishment data.
} 
FIGURE 1A: VALUE ADDED AND EMPLOYMENT TOTAL MANUFACTURING, 1959-89
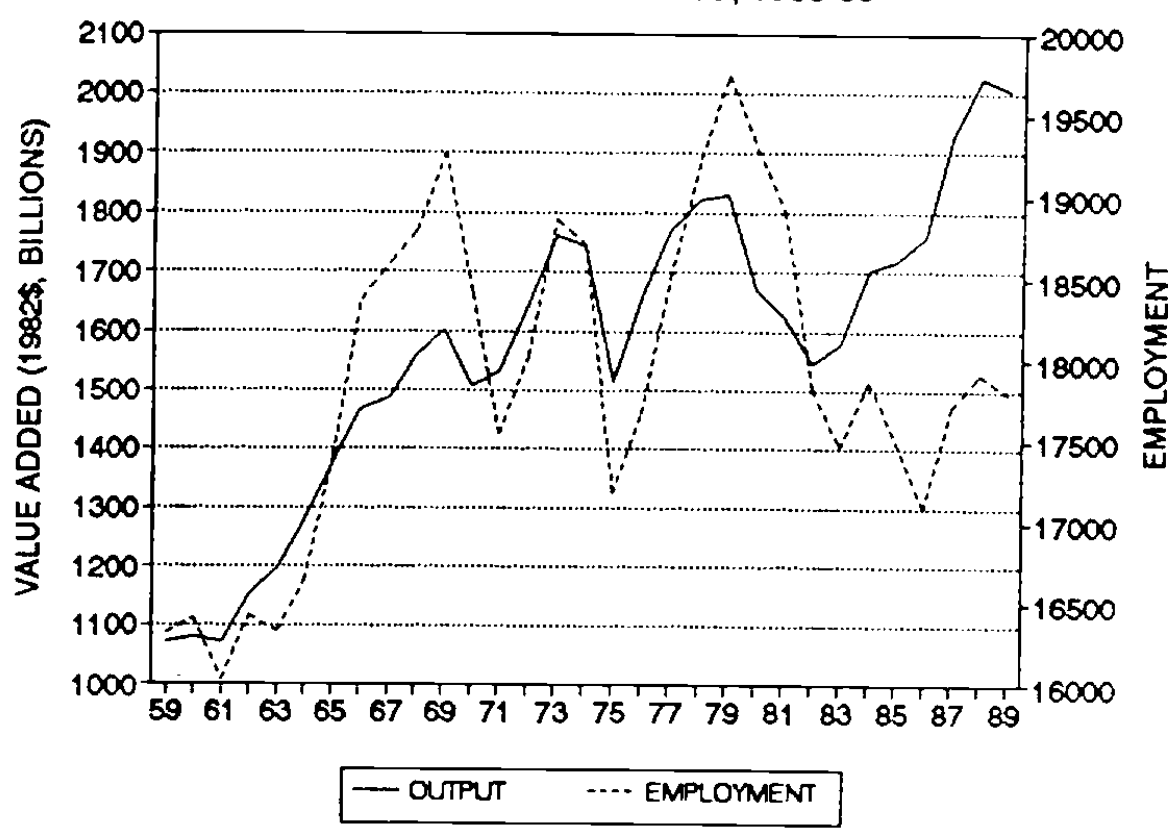

FIGURE 1B: AVERAGE LABOR PRODUCTIVTY GROWTH, TOTAL MANUFACTURING, 1960-89

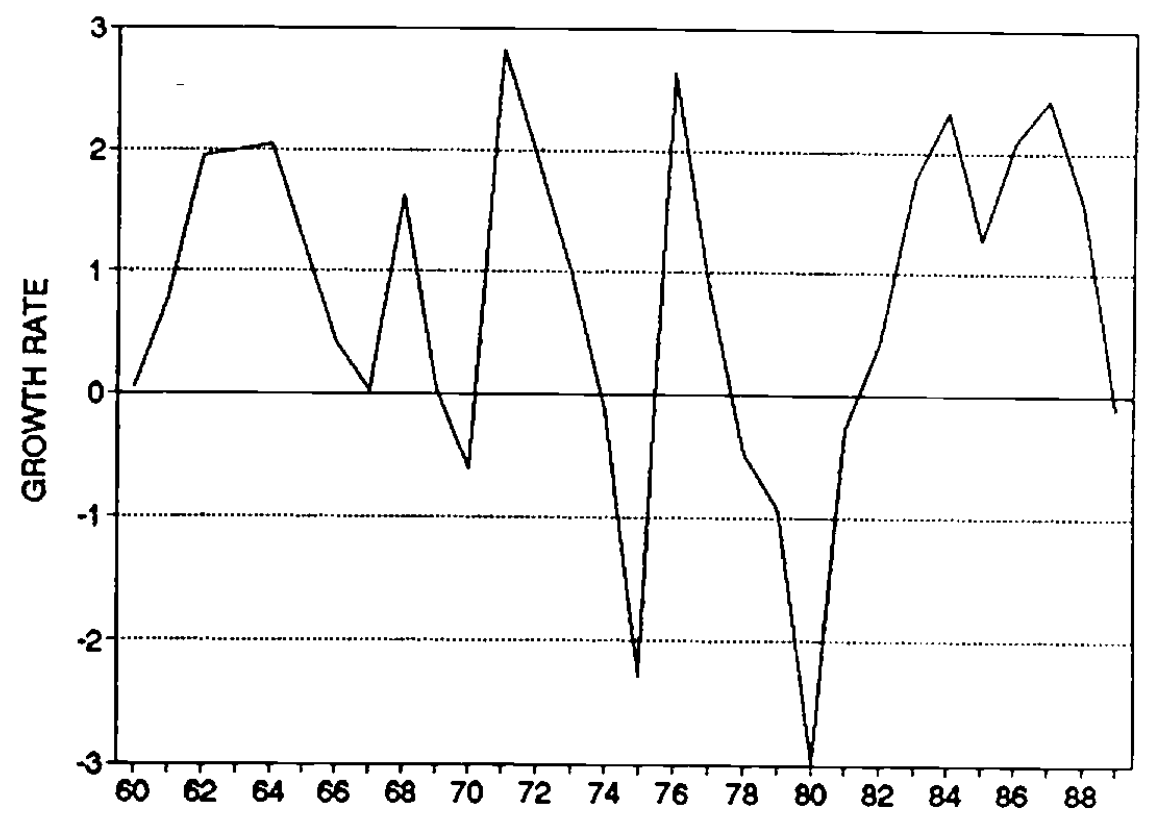


FIGURE 2: ESTABLISHMENT AND COWORKER MEAN, TOTAL MANUFACTURING, 1962-88

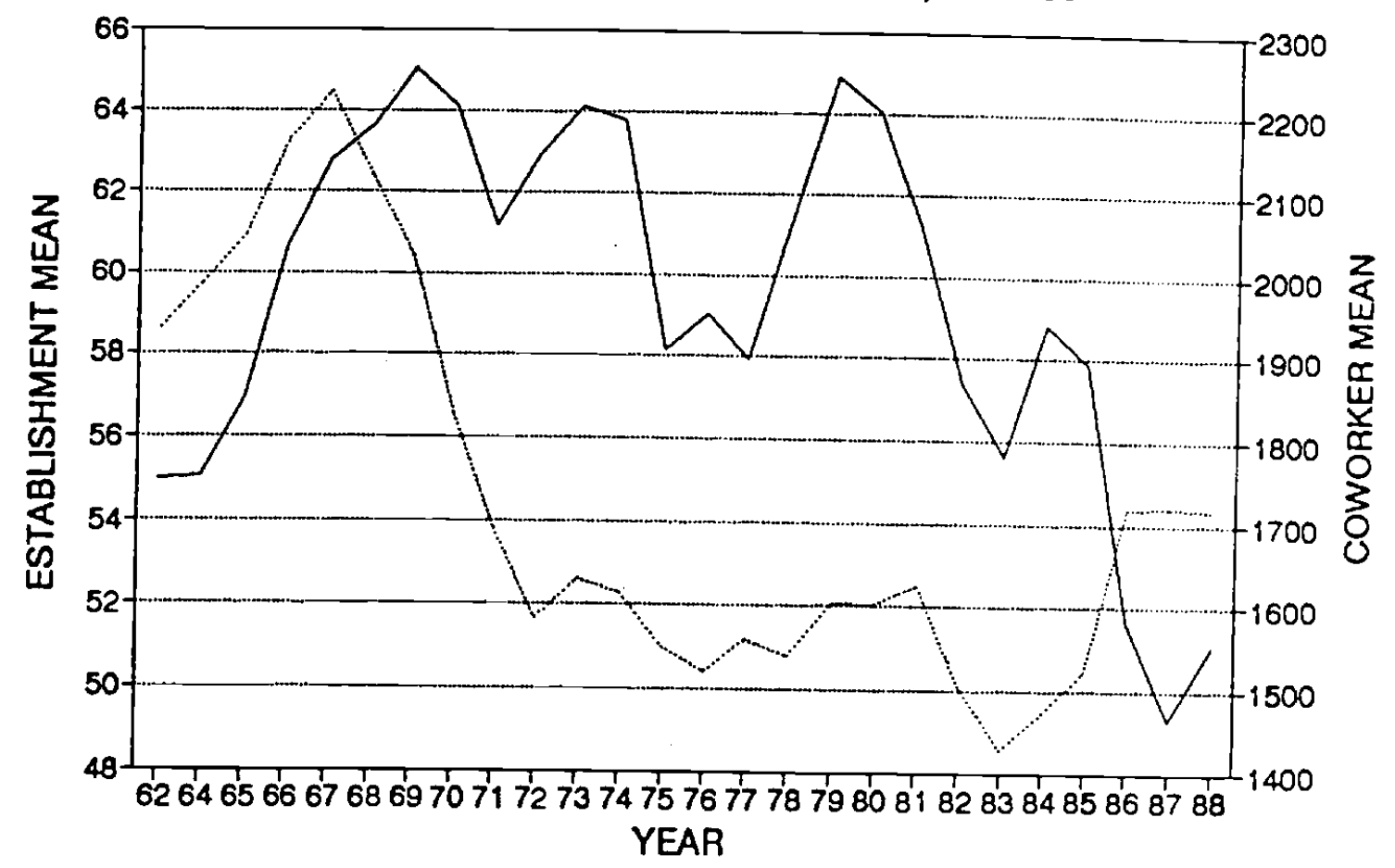

ESTABUSHMENT MEAN - COWORKER MEAN 
It turns out, however, that it is quite misleading to draw inferences from these aggregate data to cliaracterize what has been happening at the micro level to individual plants. Baily, llulten. and Campbell (1992) and Bartelsman and Dhrymes (1992) describe the effects that composition changes have on the translation of plant level productivity to aggregate productivity behavior. They find that growth in aggregate Total Factor Productivity is mostly the result of changes in output shares between plants, rather than within plant increases in TFP.

Another related example of the pitfalls of relying on aggregate data can be found in Davis and Haltiwanger (1990). As shown in figure 2, the mean establishment size (as measured by published total manufacturing employment divided by total number of establishments) fell from 58 workers in 1977 to less than 50 workers in 1987. This fact, based on aggregate data, seemingly provides evidence of significant downsizing over this period. However, the size distribution of plants is very skewed-while the typical plant is small, the typical worker works for a large plant. Davis and Haltiwanger define a summary statistic denoted the coworker mean, which is the employment. weighted average size of an establishment and thus represents the size of the plant for the typical worker. ${ }^{2}$ The coworker mean is more than an order of magnitude larger than the mean plant size; the typical manufacturing worker in 1987 is employed at a plant with more than 1700 employees. More telling for our story is that the coworker mean, shown on the right axis of figure 2 , fell in the late 1960 s and early 70 s, before the full impact of international trade was felt. It actually has increased slightly from 1977 to 1987.

The finding that the size of the establishment for the typical worker has not declined in recent years is striking in light of the conventional wisdom on downsizing. This turns out to be just the first glimpse of the noisy, complex process of employment, output and productivity growth at the plant level. Recent work using plant level data (e.g., Davis and Haltiwanger (1990, 1992), Dunne, Roberts and Samuelson (1989), Baily, Campbell and Hulten (1992), Bartelsman and Dhrymes (1992), Baldwin and Gorecki $(1990,1991)$ ) present a picture of a disperse distribution of output. employment and productivity growth rates that varies in both location and shape over time. We

\footnotetext{
${ }^{2}$ Hart (1973) presents a variety of alternative summary statistics that could be used to characterize the skewed nature of the size distribution. In the terminology of Hart, the coworker mean is the ratio of the second moment 10 the first moment about zero of the employment size distribution of plants.
} 
have learned from this work that when the aggregate economy grows, for example, this is accounted for by some plants growing and others contracting with the gross rates of change very large relative to the net change. This paper continues in that tradition with a focus on the connection between employment growth and productivity growth at the plant level and the associated implications for aggregate employment and productivity grow:th.

As with prior studies, we find there is substantial heterogeneity among plants and industries. While layoffs often receive more publicity than do employment increases, there are in fact many manufacturing establishments where productivity growth accompanies increases in employment. Overall, plants that added workers contribute about the same to aggregate productivity as plants that downsized. Similarly, while downsizing is associated with increases in productivity, there are in fact many establishments where a reduction in employment accompanies productivity losses. Further, there are striking differences by sector (defined by industry, size, region and ownership type) in the allocation of plants in terms of whether they upsize or downsize and whether they increase or decrease productivity. While the detailed industry, region, size, ownership type and wage characteristics of plants do provide statistically significant information on the probability that a given plant is a downsizing productivity gainer. we find that most of the cross.sectional variance of productivity and employment growth rates cannot be explained by observable plant characteristics. Thus, the allocation of plants in terms of whether they upsize or downsize, increase or decrease productivity is largely driven by idiosyncratic factors.

\section{THE DATA}

Our primary dataset consists of all manufacturing plants that were in operation in both 1977 and 1987 as reported to the Censuses of Manufacturers (the "continuers"). There are about 140,000 such plants. We will also present some information about those plants that were in operation in 1977 , but that had shut down by 1987 (the "exiters"); and also for the new plants that started between 1977 and 1987 (the "entrants"). Because of the difficulty of matching plant identification numbers there is some error in allocating plants to the continuers, exiters and entrants. but we believe that this error is small. ${ }^{3}$

\footnotetext{
${ }^{3}$ Davis and Haltiwanger and Schuh (1994) describe the methodology for using the coverage code information in
} 
In our investigation, we consider both gross output and value added based measures of labor productivity. Gross output for our plants is measured as shipments adjusted for inventories, defated by the 4-digit deflator for the industry in which the plant is classified. Labor input is the total employment of the plant and labor productivity, using the gross output method, is the ratio of the two. Value added is constructed for our plants by subtracting the real cost of materials from the gross out put measure. The real cost of materials is measured as the dollar cost of materials deflated by a 4-digit material deflator. The value added measure of labor productivity is accordingly the ratio of plant level value added to plant level employment. In all cases, the results are reported in terms of 1982 dollars. We specifically chose the midpoint of our sample to minimize the distortions associated with using a fixed weight price index in this context. ${ }^{4}$ Most of our results are presented in terms of the value added measure of labor productivity. We do this for a number of reasons. First, this is the conceptually preferable measure of labor productivity. Second, in spite of concerns about measurement error in both the plant level materials data as well as in the materials deflators, we find that the results are very similar with the gross output based measure. ${ }^{5}$

There are a number of relevant measurement concerns given our data and methodology that should be noted in interpreting our results. First, even for our value added based measure, we do not include the effect of purchased services. This is a concern since there is some evidence that the manufacturing sector has increased its outsourcing, particularly its purchases of services; our value added measure will capture increased outsourcing if it is the form of intermediate physical inputs but will not capture changes in the role of purchased services. In addition, our labor measure-establishment level employment-neglects employees in auxiliary establishments such as head-office and R\&D facilities. Note that Siegel and Griliches (1991) investigate the role of both of these measurement issues and conclude that they do not have much of an effect on the measurement of manufacturing productivity for the period $1977-82$ (one half of our sample period). This provides some reassurance that these measurement concerns are not likely to have a serious impact on our

the plant level data to clean up residual matching problems in the LRD. In this work we match solely on the basis of Census permanent plant number (ppn).

'In an earlier version of this paper, we used 1977 as a base year. This yields a higher growth rate of output and productivity since doing 20 overstates the contribution to real output of industries with declining relative prices. especially for computers.

${ }^{3}$ We report some of the key results using both methods to verify this claim. 
results.

We recognize as well that our focus on labor productivity rather than total factor productivity affects the interpretation of our results. The role of capital deepening and biases in technical change cannot be well understood by the behavior of labor productivity alone: for example, invest ments in labor saving equipment which increase labor productivity may not be successful from a TFP point of view.

Table 1 gives summary statistics of productivity, employment and output for all of manufacturing, for our primary sample of 140,000 continuing plants, and for the exiters and entrants. The results in Table 1 are based on the value added measure and are restricted to plants with pos. itive value added and materials purchases in the relevant years for the different types of plants (e.g., continuers must have positive value added in both years). We see that productivity grew' by 38.7 percent for the sector as a whole for the ten year period. while the continuers had productivity growth of 33.9 percent. ${ }^{6}$ It follows that the plants that entered between $197 i$ and $198 ;$ had lower average labor productivity than the plants that exited. Plant turnover thus has a small net negative effect on productivity (there is a small net positive effect when productivity is cal. culated from gross output). As seen, the labor productivity of exiters was substantially lower than that of the continuers, while it was not the case that entrants came in at higher than average productivity-consistent with the findings of Bartelsman and Dhrymes (1992). Decomposing the relative contribution of continuing plants and net entry, the increased productivity of the net entrants accounts for approximately $30 \%$ of the overall increase in productivity from $1977-87$. ;

As shown in table 1, manufacturing employment declined by 0.45 per year. ${ }^{8}$ Our main sample of continuers accounted for employment of 12.8 million in 1977 and (somewhat surprisingly perhaps) had just a small loss of 98,000 employees by 1987 . Job destruction among the continuers thus has been almost fully offset by job creation by this same group (the job loss is only 30,000 if the

\footnotetext{
${ }^{B}$ The figures reported in the table are the average growth over 10 years (cumulative growth divided by 10 ) rather than the annualized growth rate. We use this average growth measure in all of our tables so that our decompositions add up properly. The implied annual growth rate for productivity is 2.85 percent.

'Interestingly, the contribution of net entry falls to $20 \%$ if industry 357 (computing equipment) is excluded from the calculation.

"Note that for the entire sample, including those with negative value added. employment declined by 0.42 per year.
} 
Table 1: Summary Statistics for Census of Manufacturers

Labor Productivity

\begin{tabular}{lrrr} 
& $197 i$ & 1987 & Change $^{*}$ \\
\hline All & 53 & 73 & 3.87 \\
Continuers & 56 & 75 & 3.39 \\
Entrants & & 67 & \\
Exiters & 44 & & \\
\hline
\end{tabular}

Employment (000s)

\begin{tabular}{lrrr} 
& $19 i 7$ & 1987 & Change $^{*}$ \\
\hline All & 17850.791 & 17051.302 & -0.45 \\
Continuers & 12776.966 & 12679.236 & -0.08 \\
Entrants & & 4372.066 & \\
Exiters & 5073.825 & & \\
\hline
\end{tabular}

Value Added (1982 \$, millions)

\begin{tabular}{lrrr} 
& 1977 & 1987 & Change $^{*}$ \\
\hline All & 938 & 1242 & 3.25 \\
Continuers & 716 & 952 & 3.29 \\
Entrants & & 291 & \\
Exiters & 222 & & \\
\hline
\end{tabular}

- Average Gronth over 10 years, not at an annual rate 
negative value added plants are included). The net reduction in manufacturing employment has come about primarily from layoffs at plants that were closed which were not fully offset by hires at new plants.

The rate of output growth has been about the same in the continuers as in the whole sector. As a group, the continuers are consistent with the conventional wisdom - rapid output growth. nild enployment contraction, and rapid productivity growth. ${ }^{9}$

\section{PRODUCTIVITY AND EMPLOYMENT QUADRANTS}

In the remainder of this paper we concentrate on the continuing plants. We have divided these continuing plants in our sample into four groups or quadrants, as illustrated in Figure 4. Quadrant 1 consists of the "successful upsizers," plants that were able to increase both labor productivity and employment. Quadrant 2 are the "successful downsizers," the plants that raised productivity but did so by reducing employment. Quadrant 3 are the "unsuccessful downsizers," the plants that faced reductions in both productivity and employment. Finally, the quadrant 4 plants are the unsuccessful upsizers, the plants that raised employment but at the expense of productivity.

Figure 5 shows the average annual percentage change in labor productivity, employment. and output for total manufacturing, and for the average plant in each quadrant. This figure illustrates clearly that productivity growth can occur by plants increasing or decreasing employment (quadrants 1 and 2), and that layoffs do not necessarily lead to successful increases in productivity (quadrants 2 and 3 ).

Plants can find themselves in quadrant 1 for a variety of reasons. First, the long run increase in both labor productivity and employment is consistent with increased demand for its products combined with increasing returns technology. Alternatively, these plants could have actually moved their production frontier outward through technological innovation, while facing elastic product demand.

\footnotetext{
${ }^{9}$ Shown in Table A.1 in the appendix are the summary statistics for the manufacturing sector excluding industry 357, computer equipment. This industry has shown extraordinary productivity growth captured by the rapidly falling deflator for computer equipment. With this industry removed from the total, productivity increase drops to 2.99 percent a year for the whole sector and to 2.89 percent for the continuers. Comparing these results to the results for total manufacturing shows that 357 by itself has obviously accounted for a non-trivial share of the sector's productivity increase. Note that the relative contribution of industry $35 T$ is affected by the choice of the base year. The relative contribution increases if 1977 is chosen as the base year and decreases if 1987 is chosen as the base year.
} 
Figure 3: EMPLOYMENT IN U.S. MANUFACTURING ESTABLISHMENTS 1977 AND 1987

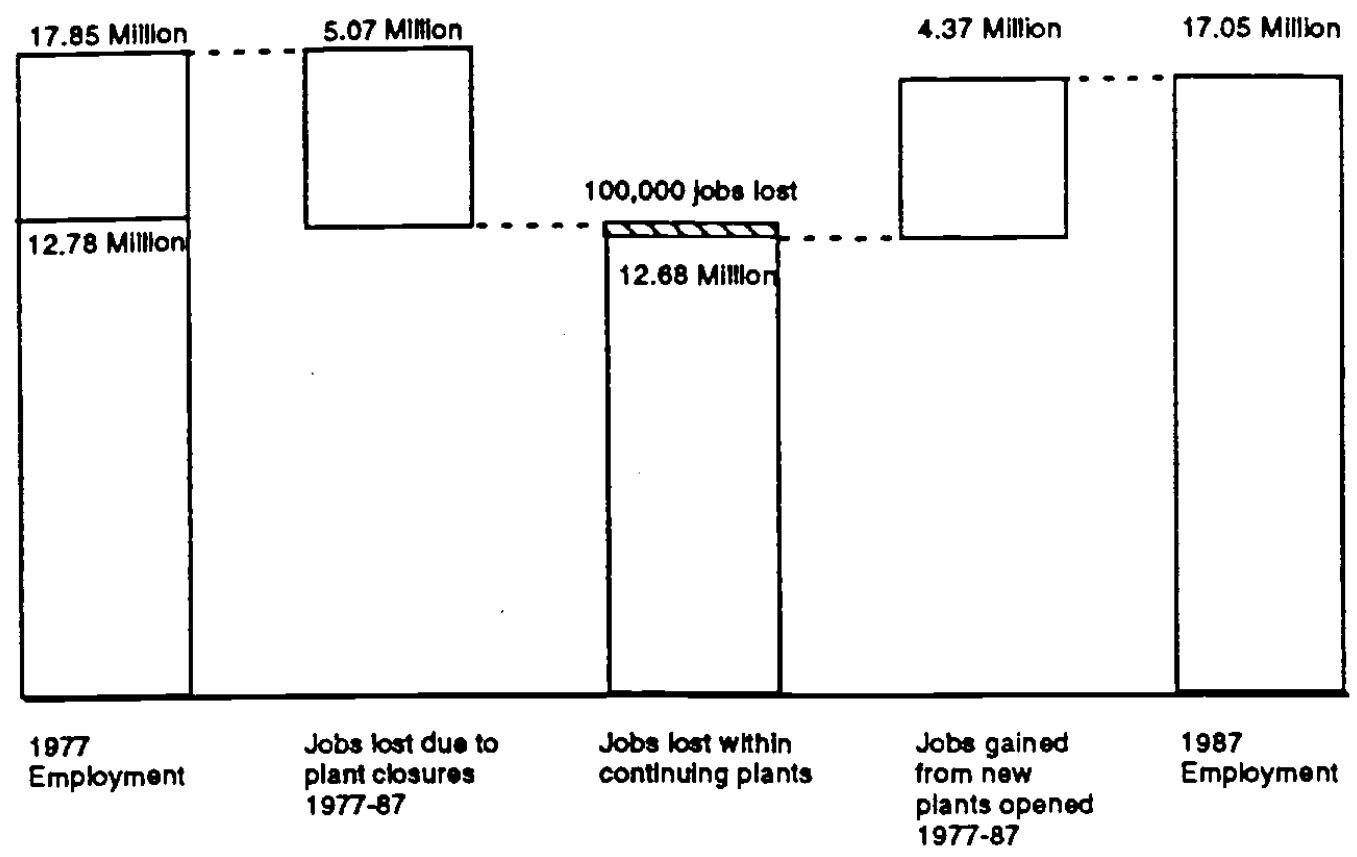

Note: Excludes plants with negative value added.

I1MOM1DDEE 
Figure 4: Employnent and Productivity Changes, 19i-i-198i

\begin{tabular}{c|c} 
QUADRANT II & QUADRANT I \\
Successful Downsizers & Successful Upsizers \\
$\Delta$ Productivity $>0$ & $\Delta$ Productivity $>0$ \\
$\Delta$ Employment $<0$ & $\Delta$ Employment $>0$ \\
& \\
& \\
QUADRANT III & QUADRANT IV \\
Unsuccessful Downsizers & Unsuccessful Upsizers \\
$\Delta$ Productivity $<0$ & $\Delta$ Productivity $<0$ \\
$\Delta$ Employment $<0$ & $\Delta$ Employment $>0$
\end{tabular}

The conventional wisdom about I.S. manufacturing over this period is captured in the quadrant 2 plants. These were the ones that raised productivity, but did so at the expense of jobs. This pattern is consistent with technological innovation combined with either falling demand or very inelastic demand (labor augmenting technical change is suggested in either case). If there were a simple way to characterize the whole manufacturing sector, then we should find that the bulk of manufacturing output and employment would be in plants in quadrant 2.

The employment and productivity behavior of plants in the third quadrant are consistent with one of the following (i) falling demand and increasing returns to scale or (ii) negative productivity shock and elastic demand or (iii) falling demand and incomplete adjustment of employment. Based on this last interpretation, which we find the most plausible, we label these plants unsuccessful downsizers.

The final group of plants are those where falling productivity and rising employment place them in quadrant 4. The pattern here is consistent with a negative productivity shock and inelastic demand, or rising demand and diminishing returns. Alternatively, these plants could have shifted to lower quality employees, which could be observed by falling wages. We examine this hypothesis below.

WITHIN-PLANT PRODUCTIVITY GROWTH AND MIX EFFECTS 


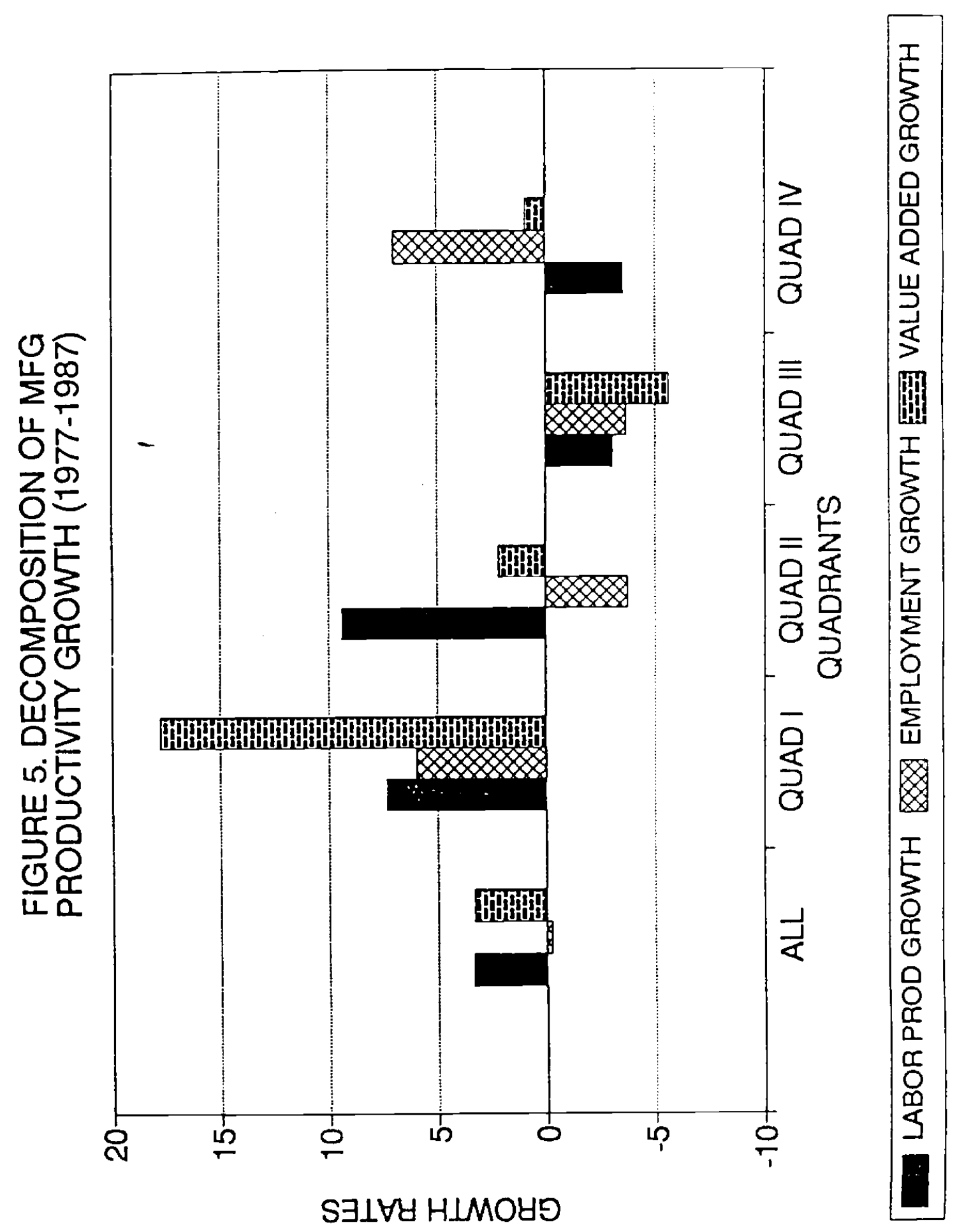


Table 2: Summary Statistics, by Quadrant. 19i7-198i

\begin{tabular}{lrrrrr} 
& All Plants & $\Delta \Pi>0$ & $\Delta \Pi>0$ & $\Delta \Pi<0$ & $\Delta \Pi<0$ \\
& & $\Delta L>0$ & $\Delta L<0$ & $\Delta L<0$ & $\Delta L>0$ \\
\hline Estab. & 140501 & 44597.0 & 36238.0 & 19289.0 & 40377.0 \\
pct. & 1.00 & 31.74 & 25.79 & 13.73 & 28.74 \\
Empl. pct. 77 & 1.00 & 23.91 & 44.79 & 18.80 & 12.49 \\
Empl. pct. 87 & 1.00 & 38.50 & 28.21 & 11.91 & 21.38 \\
Empl. Growth & -0.08 & 5.98 & -3.75 & -3.71 & 6.98 \\
VA pct. 77 & 1.00 & 20.22 & 40.50 & 23.38 & 15.90 \\
VA pct. 87 & 1.00 & 42.26 & 37.01 & 7.66 & 13.07 \\
VA Growth & 3.29 & 17.77 & 2.14 & -5.65 & 0.92 \\
Labor Prod. Growth & 3.39 & 7.38 & 9.43 & -3.08 & -3.57 \\
productivity & 4.30 & 7.51 & 10.08 & -3.37 & -3.22 \\
empl. share & 0.01 & -0.36 & 0.30 & 0.23 & 0.03 \\
cross term & -0.92 & 0.23 & -0.94 & 0.06 & -0.38 \\
Contribution to Labor Prod. Growth & & & & \\
by quadrant & 3.39 & 2.18 & 2.56 & -0.62 & -0.73 \\
productivity & & 1.49 & 3.82 & -0.72 & -0.57 \\
empl. share & & -0.23 & 0.16 & -0.17 & 0.24 \\
cross term & & 0.91 & -1.41 & 0.26 & -0.40 \\
\hline
\end{tabular}

In Table 2 we show how the plants in our main group of 140.000 continuers break down into the four quadrants using the value added measure of labor productivity. There are between one-quarter and one-third of the plants in each of quadrants 1,2 , and 4 . There are 14 percent of the plants in quadrant 3.

Counting the number of plants may not be the most revealing way to see the relative importance of each quadrant, however, and table 2 also shows the employment and output shares. We see that the quadrant 1 and 2 plants make up the bulk of the sector in both employment and output. They account for two thirds or more of the sector both in 1977 and 1987. The large number of somewhat anomalous quadrant 4 plants are smaller than average.

The middle rows of the table give a decomposition for all the plants and for each quadrant separately that indicates how much of the productivity growth reflects increases within individual plants (the row labelled "productivity") and how much comes from mix effects (the rows labelled "employment shares" and "cross terms"). Equation 1 shows the decomposition underlying these 
three rows in the table.

$$
\frac{\Delta \Pi_{t}}{\Pi_{t-1}}=\frac{\sum_{i} \phi_{l-1, i} \Delta \Pi_{t, i}}{\Pi_{t-1}}+\frac{\sum_{i} \Delta \phi_{t, i}\left(\Pi_{t-1, i}-\Pi_{t-1}\right)}{\Pi_{t-1}}+\frac{\sum_{i} \Delta \phi_{l, i} \Delta \Pi_{t, i}}{\Pi_{t-1}}
$$

where $\phi_{i}=\frac{L_{1}}{\sum_{i} L_{i}} \cdot{ }^{10}$

The first mix term (labeled "empl. share") ariscs because of shifts in employment shares between plants. This term is positive or negative depending upon whether the plants that are above average in productivity are increasing or decreasing their shares of employment. ${ }^{11}$ The table shows that for all plants together the term is positive, but very small. Within quadrants, this cross term is negative for the plants in quadrant 1 , but positive for those in quadrants 2 and 3 . It is essentially zero for the plants in quadrant 4.

The second mix effect (the row labeled "cross term") is positive or negative depending upon whether plants that have positive productivity growth have increasing or decreasing employment shares, respectively, or vice-versa. This term is negative overall, indicating that plants that have positive productivity growth do on average have decreasing employment. It alternates in sign among the quadrants (as it must given their definitions) - the Quadrant 2 plants are dominating the cross term.

Although there are non trivial mix effects shown in these data, it seems that a fair general characterization of the results is that most of the overall increase in productivity and most of the increase within each quadrant is accounted for by within plant changes. The changes in productivity over the ten year period are not the result of mix effects. This finding is consistent with that of Griliches and Regev (1992), who look at the decomposition of labor productivity in Israeli manufacturing plants. Interestingly, it contrasts with the finding of Bartelsman and Dhrymes (1992) that TFP growth is mostly a result of mix shifts in the long run.

\section{CONTRIBUTIONS TO OVERALL GROWTH BY QUADRANT}

The bottom four rows of Table 2 treat each quadrant as a group and ask how much each

\footnotetext{
${ }^{10}$ To ensure that these terms add up properly, the percentage change between 1977 and 1987 is divided by 10 to get the average growth. Unless otherwise stated, growth rates are not calculated at an average annual rate.

${ }^{11}$ Note that the inclusion of the average productivity term, $\Pi_{t-1}$, is possible because $\sum_{1} \Delta \phi_{t, i}=0$.
} 
group contributes to overall productivity growth. Quadrants 1 contributes almost two-thirds of the overall growth. Quadrant 2 accounts for about three-quarters of the overall growth. Thus, these two quadrants together account for more than the total increase in productivity as their contributions are offset by quadrants 3 and 4 .

It is important to emphasize that each quadrant contributes not only through its own change in productivity, but also because its share of employment is changing. Equation 2 show's how this happens.

$$
\frac{\Delta \Pi_{t}}{\Pi_{t-1}}=\frac{\sum_{q} \phi_{t-1, q} \Delta \Pi_{t, q}}{\Pi_{t-1}}+\frac{\sum q \Delta \phi_{t, q}\left(\Pi_{t-1, q}-\Pi_{t-1}\right)}{\Pi_{t-1}}+\frac{\sum_{q} \Delta \phi_{t, q} \Delta \Pi_{t, q}}{\Pi_{t-1}}
$$

where $\phi_{q}=\frac{L_{q}}{\sum_{q} L_{q}}$, the share of manufacturing labor in quadrant $q, \Pi_{q}=\frac{Q_{q}}{L_{q}}$, and $Q_{q}=\sum_{i \in q} Q_{i}, L_{q}=$ $\sum_{i \in q} L_{i}$

Given equation 2, we see that quadrant 1 plants contribute both by the rise in productivity at each of these plants but also through the increased employment share (the positive cross term). The contribution of quadrant 2 coming from rising productivity (holding employment shares fixed) is higher than that of quadrant 1 , even though the plants in these quadrants have about these same productivity growth rates, on average. This is the result of the negative impact of the falling employment shares (shown by the negative cross term) in quadrant 2.

Quadrants 3 and 4 both contribute negatively to overall productivity. For quadrant 3 , much of this is due to decreases in productivity holding the employment share fixed. While this is an important component for quadrant 4 as well, the increase in employment share combined with the decrease in employment is also an important, contributing factor. ${ }^{12}$

\section{QUADRANT DECOMPOSITION USING GROSS OUTPUT MEASURE}

The analogous results using the gross output measure are reported in Table 3 . The results are strikingly similar to those obtained using the value added measure. The shares of plants, employment and output across quadrants are very similar across both measures. Or particular

\footnotetext{
${ }^{12}$ In the appendix Table A.2 we show the same calculation, but with the computer equipment industry removed from the sample. The main impact is on the quadrant 1 plants. This group now contributes 1.88 percent rather than 2.18 percent to overall productivity growth.
} 
Table 3: Summary Statistics, by Quadrant, 19ii-198i. Gross Output

\begin{tabular}{lrrrrr} 
& All Plants & $\Delta \Pi>0$ & $\Delta \Pi>0$ & $\Delta \Pi<0$ & $\Delta \Pi<0$ \\
& & $\Delta L>0$ & $\Delta L<0$ & $\Delta L<0$ & $\Delta L>0$ \\
\hline Estab. & 146525 & 43881.0 & 37521.0 & 20541.0 & 44582.0 \\
pct. & 1.00 & 29.95 & 25.61 & 14.02 & 30.43 \\
Empl. pct. 77 & 1.00 & 24.22 & 45.40 & 17.78 & 12.61 \\
Empl. pct. 87 & 1.00 & 38.83 & 28.30 & 11.24 & 21.63 \\
Empl. Growth & -0.03 & 5.99 & -3.78 & -3.69 & 7.11 \\
Q pct. 77 & 1.00 & 19.59 & 43.33 & 21.01 & 16.07 \\
Q pct. 87 & 1.00 & 39.03 & 36.45 & 8.96 & 1.5 .57 \\
Q Growth & 2.18 & 14.27 & 0.24 & -4.81 & 1.79 \\
Labor Prod. Growth & 2.21 & 5.17 & 6.47 & -1.76 & -3.11 \\
productivity & 3.11 & 5.51 & 6.81 & -2.48 & -2.51 \\
empl. share & -0.11 & -0.55 & 0.44 & 0.61 & -0.24 \\
cross term & -0.79 & 0.21 & -0.78 & 0.10 & -0.36 \\
Contribution to Labor Prod. Growth & & & & \\
by quadrant & 2.21 & 1.35 & 1.83 & -0.35 & -0.61 \\
$\quad$ productivity & & 1.01 & 2.81 & -0.37 & -0.50 \\
empl. share & & -0.28 & 0.08 & -0.12 & 0.25 \\
cross term & & 0.61 & -1.06 & 0.14 & -0.36 \\
\hline
\end{tabular}

interest is the fact that the share of plants in quadrant $\mathbf{4}$ is about the same with both measures of labor productivity. Thus, it does not appear as if changes in the extent or nature of outsourcing is an important factor in accounting for the somewhat anomalous plants in quadrant 4 .

Broadly, the respective contributions of each of the quadrants to productivity grow'th and the associated decompositions of these effects are also very similar with the gross output based measure. The importance of quadrant 1 in accounting for the increase in productivity is slightly louer (about $61 \%$ ) using the gross output measure, while the contribution of quadrant 2 is somewhat larger (about $82 \%$ ). Thus, corrections for changes in materials usage does lower the contribution of successful downsizers somewhat which is consistent with a modest role for outsourcing in accounting for the differences in results between Tables 2 and $3 .{ }^{13}$

\section{ALLOCATION OF PLANTS INTO QUADRANTS, BY SECTOR}

\footnotetext{
${ }^{13}$ Given the striking similarity in results in Tables 2 and 3 , results in subsequent sections are reported only for the value added measure. As with Tables 2 and 3 , the subsequent results are very similar using either measure.
} 


\section{INDUSTRY AND PRODUCTIVITY}

Table 4 presents the allocation of employment into quadrants (and the overall contribution to growth) by industry. In Table 4 we show the division by 2-digit industry and in the appendix describe results from the 3-digit break down. The first column of the table shows the contribution of each industry to the overall productivity increase of 3.4 percent a year. By far the largest contribution to overall productivity comes from industry 35 (non-electrical machinery) and within this industry, it is 357 (office and computing equipment) that accounts for most of this. After industry 35 , the next largest and roughly equal contributions come from industry 36 (electrical and electronic equipment) and industry 20 (food). Within this former industry it is 366 (communication equipment and 367 (electronic components) that provide most of the positive impact. The growth of the three industries 357,366 and 367 reflects the electronics revolution. If these three were excluded from the continuers, they would reduce the overall rate of productivity growth from 3.4 percent a year to 2.6 percent a year. The contributions from industry 20 (food) are scattered among the different three digit elements within this industry.

The remaining columns depict the allocation of employment by quadrant for each industry, deviated from the total manufacturing shares. At the 2-Digit level industries 28 (chemicals). 29 (petroleum refining), 31 (leather goods) and particularly 33 (basic metals) are the ones that bave less than the average share in quadrant 1 and more than the average in quadrant 2 or $3 .^{14}$ Thus, the well-known downsizing in the steel industry with the shift towards mini-mills is reflected in these results. Overall, these industries have many plants in mature products and have reduced employment to increase productivity. However, generalizations by two-digit industry are difficult to make since, as shown in the appendix, there is a wide variance of experience within the same two-digit industry.

\section{REGION AND PRODUCTIVITY}

Table 5 presents results for Census region in the same format as those presented in table 4 . New England, West North Central, South Atlantic, Mountain and Pacific regions had above average

\footnotetext{
${ }^{14}$ Excluding computers (SIC 357), the remainder of industry 35 also falls squarely into this group
} 
Table 4: Sumıary Statistics, by Industry

\begin{tabular}{|c|c|c|c|c|c|}
\hline Industry & $\Delta \Pi^{1}$ & Quad I & Quad II & Quad III & Quad IV:2 \\
\hline \multirow[t]{2}{*}{ All Plants } & 3.3895 & 31.18 & 36.53 & 15.37 & 16.92 \\
\hline & & \multicolumn{4}{|c|}{ Deviations from above distribution } \\
\hline 20 & 0.4056 & 2.13 & -3.99 & -3.35 & 5.21 \\
\hline 21 & 0.0087 & 1.47 & -6.34 & 18.30 & -13.43 \\
\hline 22 & 0.1213 & 2.05 & 9.61 & .5 .07 & .6 .59 \\
\hline 23 & 0.1278 & 0.96 & 3.65 & -2.01 & -2.60 \\
\hline 24 & 0.0616 & 2.45 & -1.55 & .1 .91 & 1.02 \\
\hline 25 & 0.0169 & 5.26 & -8.19 & -1.63 & 4.56 \\
\hline 26 & 0.1508 & 0.36 & 2.04 & -2.10 & .0 .29 \\
\hline 27 & 0.0397 & 3.05 & -14.05 & -5.99 & 16.99 \\
\hline 28 & 0.3749 & -5.55 & 7.97 & -2.27 & .0 .16 \\
\hline 29 & 0.2581 & -7.13 & 20.12 & $\cdot 7.24$ & -5.76 \\
\hline 30 & 0.1294 & 7.76 & 0.08 & -4.54 & -3.30 \\
\hline 31 & 0.0157 & -9.63 & 7.20 & 5.63 & -3.21 \\
\hline 32 & 0.0515 & -5.24 & 1.40 & 3.03 & 0.82 \\
\hline 33 & 0.1232 & -15.51 & 21.65 & 3.16 & -9.30 \\
\hline 34 & 0.1529 & -2.99 & 2.92 & 1.66 & $\cdot 1.58$ \\
\hline 35 & 0.5685 & -6.91 & 1.41 & 7.68 & -2.17 \\
\hline 36 & 0.4019 & 12.10 & -5.23 & -2.32 & -4.54 \\
\hline 37 & 0.2182 & 1.60 & $\cdot 9.95$ & 5.17 & 3.18 \\
\hline 38 & 0.1359 & -2.17 & 7.42 & -2.52 & -2.73 \\
\hline 39 & 0.0270 & -2.58 & 0.08 & -0.29 & 2.79 \\
\hline $\begin{array}{l}\text { I: } \Delta \mathrm{n}>0 \\
\text { III: } \Delta \mathrm{n}< \\
\text { Contrib }\end{array}$ & $\begin{array}{l}>0 \\
L<0\end{array}$ & $\begin{array}{l}\text { II: } \Delta \Pi \\
\text { IV: } \Delta \Pi \\
\text { produc }\end{array}$ & $\begin{array}{l}\Delta \mathrm{L}<0 \\
\Delta \mathrm{L}>0 \\
\text { y growth }\end{array}$ & & \\
\hline
\end{tabular}


Tahle 5: Summary Statistics, by Region

\begin{tabular}{|c|c|c|c|c|c|}
\hline Region & $\Delta \Pi^{1}$ & Quad I & Quad II & Quad III & Quad IV ${ }^{2}$ \\
\hline \multirow[t]{2}{*}{ All Plants } & 3.3895 & 31.18 & 36.53 & 15.37 & 16.92 \\
\hline & & \multicolumn{4}{|c|}{ Deviations from above distribution } \\
\hline New England & 0.3227 & 5.96 & -1.70 & -2.62 & -1.64 \\
\hline Mid Atlantic & 0.4414 & -2.82 & 2.16 & 0.36 & 0.30 \\
\hline E.N. Central & 0.5642 & -7.97 & 5.04 & 5.44 & -2.51 \\
\hline W.N. Central & 0.2648 & 1.87 & -3.13 & -1.87 & 3.13 \\
\hline S. Atlantic & 0.5104 & 5.07 & -0.83 & -3.57 & -0.67 \\
\hline E.S. Central & 0.2798 & -0.13 & 3.74 & -0.56 & -3.05 \\
\hline W.S. Central & 0.4076 & -1.32 & -0.89 & 1.11 & 1.10 \\
\hline Mountain & 0.1259 & 7.44 & -6.44 & -3.35 & 2.35 \\
\hline Pacific & 0.4728 & 8.78 & -10.27 & -4.31 & 5.81 \\
\hline
\end{tabular}

I: $\Delta \mathrm{\Pi}>0, \Delta \mathrm{L}>0 ; \quad$ II: $\Delta \mathrm{\Pi}>0, \Delta \mathrm{L}<0$;

III: $\Delta \Pi<0, \Delta \mathrm{L}<0 ; \quad$ IV: $\Delta \Pi<0, \Delta \mathrm{L}>0$

1 Contributions to labor productivity growth

${ }^{3}$ Percent of total employment in each Quadrant

shares of their employment in quadrant 1 (successful upsizers), particularly the Pacific region. These same regions had less than average fractions of employment in quadrant 2. The sunbelt regions thus obviously were an important part of this upsizing, increasing productivity phenomenon. However, it is striking that the New England region is disproportionately represented in this group as well. ${ }^{15}$

\section{PLANT SIZE AND PRODUCTIVITY}

In table 6 we show the break down of the main sample by plant size, where this is measured by average employment in 1977 and $1987 . .^{16}$ We find that the smallest plants did not contribute much to overall growth. But after that, the contributions come from plants of a range of sizes with the highest contribution coming from plants with 500-999 employees.

\footnotetext{
${ }^{15}$ The equivalent table excluding industry 357 show that this surprising result on New England is not driven by the computer equipment industry. That is, even excluding computer equipment, New England is still disproportionately in quadrant 1.

${ }^{10}$ The use of average size to allocate plants into size classes is motivated by the findings in Davis, Haltiwanger and Schuh (1994). They show that regression to the mean fallacy problems arise in using a point in time measure of size to allocate plants into size classes given the large transitory changes in employment that are present in the plant level data.
} 
Table 6: Sumnary Statistics, by Size

\begin{tabular}{lr|rrrr} 
Size $^{1}$ & $\Delta \Pi^{2}$ & Quad I & Quad II & Quad III & Quad IV \\
\hline All Plants & 3.3895 & 31.18 & 36.53 & 15.37 & 16.92 \\
& & \multicolumn{2}{|c}{ Deviations from above distribution } \\
$1-19$ & 0.0307 & 0.05 & -12.85 & -1.40 & 14.20 \\
$20-49$ & 0.1168 & 4.03 & -9.45 & -1.88 & 7.30 \\
$50-99$ & 0.2196 & 4.37 & -7.55 & -2.37 & 5.55 \\
$100-249$ & 0.4728 & 1.73 & -3.36 & -1.05 & 2.69 \\
$250-499$ & 0.5121 & 0.16 & -0.58 & 0.69 & -0.27 \\
$500-999$ & 0.6752 & -1.52 & 3.82 & 0.88 & -3.17 \\
$1000-2499$ & 0.6024 & -5.43 & 9.12 & 2.11 & -5.80 \\
$2500-4999$ & 0.4031 & -5.82 & 12.62 & 0.86 & -7.67 \\
$5000+$ & 0.3569 & 3.30 & 0.42 & 0.51 & -4.23 \\
\hline I: $\Delta \Pi>0, \Delta \mathrm{L}>0 ;$ & II: $\Delta \Pi>0, \Delta \mathrm{L}<0 ;$ \\
III: $\Delta \Pi<0, \Delta \mathrm{L}<0 ;$ & IV: $\Delta \Pi<0, \Delta \mathrm{L}>0$ \\
1 Average of 1977 and 1987 employment, in thousands. \\
2 Contributions to labor productivity growth \\
3 Percent of total employment in each Quadrant
\end{tabular}

Small plants are disproportionately in quadrant 4 (unsuccessful upsizers). The quadrant 2 plants (successful downsizers) are disproportionately in the 500 to 4,999 size range. These are the plants that have set the stereotype for what has happened to manufacturing over the period. Strikingly, the very largest plants (over 5,000 ) have a larger than average fraction in quadrant 1 (successful upsizers) and only a small fraction in quadrant 4 (unsuccessful upsizers). Thus, not only do the upsizing, productivity gainers account for a large fraction of the aggregate productivity growth but they are disproportionately represented by the largest plants.

These findings are striking in light of the conventional wisdom on the importance of small businesses in the growth of the economy." These results indicate that small businesses that did add employment disproportionately were likely to decrease productivity. In contrast, very large businesses that increased employment disproportionately nere likely to increase productivity. ${ }^{18}$

\footnotetext{
${ }^{17}$ Davis, Haltiwanger and Schuh (1993) document the reasons why the claim that small businesses are the dominant sources of job growth is inaccurate.

${ }^{12}$ There may be a host of factors underlying this results which deserve further investigation. For example, small plants may be making unique products whose prices are not well captured by the 4 digit deflator. See also the discussion of wages below.
} 
Table 7: Summary Statistics, by Initial Wage

\begin{tabular}{|c|c|c|c|c|c|}
\hline Initial Wage & $\Delta \Pi^{1}$ & Quad I & Quad II & Quad III & Quad IV \\
\hline \multirow[t]{2}{*}{ All Plants } & 3.3895 & 31.18 & 36.53 & 15.37 & 16.92 \\
\hline & & \multicolumn{4}{|c|}{ Deviations from above distribution } \\
\hline 1st Quintile & 0.3721 & 0.49 & -2.81 & -2.39 & 4.71 \\
\hline 2nd Quintile & 0.6762 & 1.44 & -2.61 & -0.96 & 2.14 \\
\hline 3rd Quintile & 0.7961 & .0 .25 & 2.30 & 1.66 & -3.72 \\
\hline 4th Quintile & 0.9273 & -1.34 & 3.77 & 0.56 & -2.99 \\
\hline Top Quintile & 0.6179 & -2.17 & 3.28 & 5.86 & -6.97 \\
\hline \multicolumn{2}{|c|}{ Initial Wage Level } & 24.44 & 25.49 & 26.90 & 25.11 \\
\hline \multicolumn{2}{|c|}{$\begin{array}{l}\text { I: } \Delta \Pi>0, \Delta \mathrm{L}>0 \\
\text { III: } \Delta \Pi<0, \Delta \mathrm{L}<0 \\
\text { I Contributions to labe }\end{array}$} & \multicolumn{2}{|c|}{$\begin{array}{l}\text { II: } \Delta \Pi>0, \Delta \mathrm{L}<0 ; \\
\text { IV: } \Delta \Pi<0, \Delta \mathrm{L}>0 \\
\text { productivity growth }\end{array}$} & & \\
\hline
\end{tabular}

\section{WAGES AND PRODUCTIVITY}

Table 7 presents the allocation of employment into quadrants (and the overall contribution to growth) by quintiles of the level of plant real wages per worker in 1973 (in thousands of $19 \& 2$ dollars per year). Downsizing plants (quadrants 2 and 3 ) had the highest initial real wages. Unsuccessful. upsizing plants (quadrant 4 ) had slightly lower initial real wages than did the quadrant 2 plants while the successful, upsizing plants had the lowest average initial real wages.

Table 8 presents the same results by quintiles of the growth in plant real vages from 1977 to 1987. The plants that increased productivity (successful upsizers and downsizers) had the highest real wage growth, with the larger increases coming from the ones that increased employment. The plants that experienced declines in productivity had reductions in real wages, with the larger decline actually occurring in the plants that raised employment.

These results raise interesting questions about the relation among wages, employment and productivity. The first possibility is that some of the wage changes observed may be associated with changes in labor quality. Under this interpretation, successful upsizers may be adding more skilled workers, successful downsizers retaining their higher skilled workers, unsuccessful downsizers retaining their less skilled workers, and unsuccessful upsizers adding less skilled workers. A second 
Table 8: Summary Statistics, by Wage Change

\begin{tabular}{|c|c|c|c|c|c|}
\hline Wage Change & $\Delta \Pi^{\prime}$ & Quad I & Quad II & Quad III & Quad IV \\
\hline \multirow[t]{2}{*}{ All Plants } & 3.3895 & 31.18 & 36.53 & 15.37 & 16.92 \\
\hline & & \multicolumn{4}{|c|}{ Deviations from above distribution } \\
\hline 1st Quintile & .0 .0216 & .8 .06 & -12.20 & 5.18 & 15.08 \\
\hline 2nd Quintile & 0.5302 & -0.78 & -2.36 & 2.71 & 0.43 \\
\hline 3rd Quintile & 0.7802 & $4.5 t$ & $-0.5 i$ & -0.73 & -3.24 \\
\hline 4th Quintile & 0.7491 & 0.30 & 5.12 & -1.19 & -4.23 \\
\hline Top Quintile & 1.3517 & 4.03 & 10.05 & -5.99 & .8 .09 \\
\hline \multicolumn{2}{|c|}{ Mean Wage Change } & 0.69 & 1.86 & -0.27 & -0.80 \\
\hline \multicolumn{2}{|c|}{$\begin{array}{l}\text { I: } \Delta \Pi>0, \Delta \mathrm{L}>0 \\
\text { III: } \Delta \Pi<0, \Delta \mathrm{L}<0 ; \\
\text { ' Contributions to labo }\end{array}$} & II: $\Delta \mathrm{M}$ & $\begin{array}{l}\Delta \mathrm{L}<0 \\
0, \Delta \mathrm{L}> \\
\text { rowth }\end{array}$ & & \\
\hline
\end{tabular}

interpretation is that increases in the wages for certain types of workers may have led to capital/labor substitution, and vice versa for the plants with arage declines. A third possibility is rent sharing. Those plants that increased productivity gave (or were forced to give) a fraction of that increase to their workers. This would also lead to a positive relationship between the change in wages and the change in productivity. We are not able in this paper to sort out these alternative possibilities. We note, however, some suggestive points. First, the magnitudes of the rage changes are much smaller than the productivity changes. If the average skill levels or the average capital labor ratios are changing these are only a part of the reason for the productivity changes. Similarly, if rents are being shared, then only a small part of the productivity increases are being passed on to labor (as we know from aggregate manufacturing wage data). A second finding that seems clear, also, is that average wage increases are apparently not driven by the decision to expand employ. ment. The largest wage increases came from the plants with the largest rate of employment decline. One explanation of our findings that is consistent with other trends observed in manufacturing is that skill-biased technical change has occurred in many (but not all) plants. Where it has occurred, productivity has increased and at the same time there has been a relative shift in employment to higher skilled workers (raising average wages). We hope to explore these results in future research both for understanding the evolution of the distribution of productivity and the distribution of 
wages. ${ }^{19}$

\section{CONTRIBUTION OF SECTORAL CHARACTERISTICS TO OVERALL VARIANCE OF EMPLOYMENT AND PRODUCTIVITY}

Tables 4-8 show that there are striking differences across plants defined by industry, region. size, and wage in the allocation of plants into the quadrants of productivity and emplorment growth. In Table 9 we show the extent to which the characteristics of industry in 1977, region. size class, ownership type (plants associated with single-unit vs. multi-unit companies) and initial uage class can explain the variance of productivity change and employment change in the continuing plants. ${ }^{20}$ This exercise should not be interpreted as yielding causal inferences but rather a sense of the connection between observable plant characteristics and the distribution of employment and productivity growth. The table shows the $\mathbf{R}^{2}$ statistics for regressions of the column variable on the dummy variables specified in the rows. For example, the first entry in the first column shows that only 3.1 percent of the variance of productivity growth is explained by two-digit industry dummy variables. The fractions of the variance that can be explained by these variables is quite small. Even when industry, region, size class, ownership type and initial wage class are simultaneously taken into account, less than 15 percent of the overall variance in output and productivity is explained by the observable characteristics.

The last four columns of the table show the extent to which these plant-level observables can predict the allocation of plant employment into quadrants. While the explanatory power is relatively

\footnotetext{
19 Baily, Hulten and Campbell (1992) also explore the relation between wages and productivity (TFP). Their findings are consistent with these results. The McKinsey (1993) study of manufacturing productivity shows case study evidence of process and product design innovations in manufacturing (often but not always initiated in Japan) that reduced the need for anskilled workers per unit of output produced. Recent work by Hellerstein and Neumark (1993) and Hellerstein, Neumark and Troske finds a close association among between plant differences in productivity, wages, and the skill mix of the workers at individual plants.

${ }^{20}$ We do not consider the role of plant real wage growth in this context given the obvious endogeneity problems. We are treating the other observables as capturing exogenous characteristics or at least initial/predetermined conditions. Concerns about endogeneity are nevertheless relevant for the size class measure given that it represents the average size in 1977 and 1987. As discussed in footnote 16, the use of the average size rather than initial size is motivated by the results of Davis, Haltiwanger and Schuh (1994). For this purpose, a preferable method might be the average size in 1972 and 1977 since this would mitigate the transitory component problem. However, a large fraction of plants present in 1977 are not present in 1972 and thus this would reduce our sample in a s.stematic way - i.e., small plants are more likely to fail than large plants.
} 
Table 9: Percent of Variance Explained by Plant Categories

\begin{tabular}{lrrrrrr} 
Dummy & $\Delta \Pi$ & $\Delta \mathrm{L}$ & $\mathrm{Q} \mathrm{I}$ & $\mathrm{Q}$ II & $\mathrm{Q}$ III & $\mathrm{Q} \mathrm{IV}$ \\
\hline 2-digit Ind. & 3.1 & 1.8 & 1.9 & 2.9 & 1.4 & 2.4 \\
3-digit Ind. & 9.4 & 3.1 & 8.6 & 8.0 & 5.7 & 5.9 \\
4-digit Ind. & 13.0 & 4.3 & 12.5 & 11.4 & 9.8 & 10.0 \\
Size & 1.6 & 0.7 & 0.5 & 2.0 & 0.1 & 2.0 \\
Region & 0.1 & 0.3 & 1.6 & 1.0 & 1.0 & 0.5 \\
Ownership & 0.8 & 2.1 & 0.8 & 1.9 & 0.3 & 1.6 \\
Initial Wage & 2.1 & 0.9 & 0.1 & 0.4 & 0.3 & 1.1 \\
Interaction" & 14.8 & 11.8 & 26.9 & 28.4 & 22.6 & 24.5 \\
\hline \multicolumn{7}{l}{ Includes 2-dig industry, region, size, type and wage dummies }
\end{tabular}

greater here, it is still small. At most, less than 30 percent of the allocation into productivity and employment growth quadrants is accounted for by observable plant characteristics.

These results provide an important caution. They tell us that the variance of employment and productivity at the plant level are dominated by idiosyncratic effects. One interpretation of these findings is that attempts to explain differences in productivity and employment performance should concentrate on such plant-specific factors as management or worker skills. A striking message is that it is possible to raise productivity and employment even within an industry that on average is lowering productivity and employment.

It may be that there other observable characteristics that can account for the allocation of plants into employment and productivity quadrants. However, related studies also find a dominant role for the idiosyncratic component in accounting for plant level behavior. Davis and Haltiwanger (1992) find that only $39 \%$ of the allocation of employment growth into expanding and contracting plants can be accounted for by simultaneously controlling for two-digit industry, region, size, age of plant and ownership type. This amounts to controlling for over 14,000 different sectors and even within such sectors there is substantial heterogeneity in the distribution of employment growth rates.

\section{CONCLUDING REMARKS}

In contrast to the conventional wisdom, plants that raised employment as well as productivity 
contribute almost as much to overall productivity growth in the 1980 s as the plants that raised productivity at the expense of employment. Together these two groups of plants that increased productivity account for more than the total increase in productivity grouth. This is because there is an offsetting group of plants that decreased productivity over this time. Amongst the latter group, most of then are unsuccessful upsizers. That is, they increased employment but not productivity.

There are striking differences in the allocation of plants into these groups by sectoral classification. Plants in mature industries (e.g., steel) were more likely to follow the conventional wisdom. That is, they disproportionately fell into the downsizing, increasing productivity group. Plants in the sunbelt regions are disproportionately represented in the upsizing. productivity increasing group. However, plants in New England are also disproportionately represented in this group. The smallest plants are disproportionately represented in the group of plants that increased employment and decreased productivity. Strikingly, the largest plants are disproportionately represented in the group of plants that increased employment and productivity.

In spite of the striking differences across sectors defined in a variety of ways, most of the variance of productivity and employment growth is accounted for by idiosincratic factors. It is difficult to account for the allocation of plants into productivity and employment growth quadrants on the basis of observable characteristics. Thus, not only is the conventional wisdom that downsizing is the source of productivity growth incorrect but identifying who did and did not downsize and whether they were successful cannot be done with any precision on the basis of the characteristics of the plants that are reported in the Census data. 


\section{REFERENCES}

Aghion, Phillippe and Peter Howitt (1991b), "Unemployment: a symptom of stagnation or a sideeffect of growth?," European Economic Review No. 35 (2-3), April.

Baily, Martin N., Hulten, Charles and David Campbell, (1992) "The Distribution of Productivity in Manufacturing Plants." Brookings Papers: Microwiconomics, 1992.

Baldwin, John R. and Paul $k$. Gorecki (1990), Structural Change and the Adjustment Process: Perspectives on Firm Growth and Worker Turnover, Ottowa: Economic Council of Canada. Baldwin, John R. and Paul K. Gorecki (1991), "Productivity Growth and the Competitive Process: The Role of Firm and Plant Turnover", in P.A. Geroski and J Schwalbach Entry and Market Contestability: An International Comparison, Oxford: Basil Blackwell, p244-56.

Bartelsman, Eric J. and Phoebus J. Dhrymes (1992), "Productivity Dynamics: U.S. Manufacturing Plants, 19i2-1986, " FEDS working paper No. 94-1, Federal Reserve Board, January.

Bernanke, B.S. and M.L. Parkinson (1991), "Procyclical labor productivity and competing theories of the business cycle: some evidence from interwar U.S. manufacturing industries," Journal of Political Economy, 99(3), June.

Davis, Steven J., and John Haltiwanger (1990), "The distribution of employees by establishment size: Patterns of change in the U.S., 1962-1985, " draft.

Davis, Steven J., and John Haltiwanger (1992), "Gross job creation and destruction, and employment reallocation," Quarterly Journal of Economics, 107(3), pp. 819-863.

Davis, Steven J., Haltiwanger, John, and Scott Schuh (1993), "Small business and job creation: Dissecting the myth and reassessing the facts," NBER Working Paper, No. 4492.

Davis, Steven J., Haltiwanger, John, and Scott Schuh (1993), Job creation and destruction in U.S. manufacturing, (forthcoming).

Dunne, Timothy, Roberts, Mark J., and Larry Samuelson (1989), "The growth and failure of U.S. manufacturing plants," Quarterly Journal of Economics, 104(4), pp. 671-698.

Fallick, Bruce C. (1993), "The hiring of new labor by expanding industries," draft, October.

Gordon, Robert J. (1993), "The jobless recovery: does it signal a new era of productivity.led growth?", Brookings Papers on Economic Activity," v1. 
Ciriliches, Zvi, and Haim Regev, "Firm Turnover and Productivity Growth in Israeli Industry: 1979-1988", NBER Working Paper, No. xxxx, Cambridge, MA, August 1991.

Hellerstein, Judy, and David Neumark (1993), “Sex, Wages, and Productivity: An Enpirical Anal. rsis of Israeli Firm-Level Data," draft.

Hellerstein, Judy, David Neumark and Ken Troske (1994), "Wages,Productivity, and Worker Char. acteristics," draft.

Johnson, Karen H. (1994), "Productivity and Unemployment: Review of Evidence," draft.

Leonard. Jonothan S. (1988), "Technological change and the extent of frictional and structural unemployment," in R.M. Cyert and D.C. Mowery, eds., The Impact of Technological Change on Employment and Growth, Cambridge MA: Balliner Publishing Co.

Manning, A. (1992) "Productivity growth, wage setting and the equilibrium rate of unemployment," CEPR Discussion Paper No. 63.

Mckinsey (1993) Manufacturing Productivity. Report prepared by the McKinsey Global Institute with the assistance of Martin Baily, Francis Bator, Ted Hall and Robert Solow, Washington, D.C.

Mohr, Michael F, and Paul T. Christy (1986) "Changes in the Structure of the U.S. Economy Since 1960: A Primer", in Implications of Internationalization of the U.S. Economy, U.S. Department of Commerce.

Nickell, S. and P. Kong (1989), "Technical Progress and Jobs," London School of Economics, Centre for Labor Economics, Discussion Paper 366.

Nicoletti, Giuseppe and Lucrezia Reichlin (1993), "Trends and cycles in labour productivity in the major OECD countries”, OECD Economics Department Working Papers No 129.

Siegel, Donald and Zvi Griliches (1991), "Purchased Services, Outsourcing, Computers, and Productivity in Manufacturing", NBER Working Paper No. 3678, April.

Venables, A.J. (1985), " The economic Implications of a discrete technical change, ${ }^{n}$ Oxford Economic Papers 37, June. 
</ref_section> 
High fractions of employment in quadrant 1 (successful upsizers): 201 (meat products), 202 (dairy products), 225 (knitting mills), 227 (floor covering mills), 252 (office furniture), 273, 275, $27 i, 278$ and 279 (from printing and publishing), 348 ( ${ }^{2},-$ dnance), 357 (office and computing), 366 (communications), 367 (electronics), 376 (guided missiles), and 383 (optical instruments and lenses ).

High fractions of employment in quadrant 2 (successful downsizers): 204 (grain mill products), $20 i$ (fats and oils), 212 (cigars), 221, 222, 224, 226, 228 and 229 (textile mills), 231 (men's apparel), $261,262,263$, and 266 (paper mills), 282 and 286 (plastics and industrial inorganic chemicals), 291 (petroleum refining), 302 and 303 (rubber), 316 (luggage), 321 (flat glass), 324 (cement), 331 and 333 (blast furnaces and primary non-ferrous metals), 346 (metal forgings), 363 and 365 (household appliances and radio-TV), 369 (misc. electrical), 385 and 386 (ophthalmic and photographic).

High fractions of employment in quadrant 3 (unsuccessful downsizers): 211 and 213 (cigaret tes and chewing tobacco), 237 (furs), 245 (wood buildings and mobile homes), 266 (paper board), (304 (rubber and plastic hoses and belts), 311, 313,314, 315 and 319 (parts of leather and footwear), 326 (pottery), 332 and 333 (iron and steel foundries and primary nonferrous metals), 341 (metal cans), $351,352,353,354$ and 356 (engines and turbines, farm and garden equipment, construction machinery, metalworking machinery and general industrial machinery), 371 (motor vehicles and equipment), 374 (railroad equipment), 387 (watches and clocks), and 391 (jewelry).

High fractions of employment in quadrant 4 (unsuccessful upsizers): 205 (bakery products), 237 (furs), 253 and 254 (furniture for public buildings and partitions), 271, 272 and 274 (segments of publishing), 284 (pharmaceuticals, most likely a deflator problem), 299 (misc. petroleum products), 319 (misc. leather goods), 327 and 328 (concrete and cut stone), 372 (aircraft and parts), and (391 (jewelry). 


\section{A1. TABLES EXCLUDING INDUSTRY 357}

Table A.1: Summary Statistics for Census of Manufacturers

Labor Productivity

\begin{tabular}{lrrr} 
& 1977 & 1987 & Change* $^{*}$ \\
\hline All & 53 & 69 & 2.99 \\
Continuers & 56 & 73 & 2.89 \\
Entrants & & 57 & \\
Exiters & 44 & & \\
\hline \multicolumn{4}{c}{ Employment (000s) } \\
& 1977 & 1987 & Change* $^{*}$ \\
\hline All & 17661.155 & 16767.332 & -0.51 \\
Continuers & 12649.97 & 12532.558 & -0.09 \\
Entrants & & 4234.774 & \\
Exiters & 5011.185 & & \\
\hline
\end{tabular}

Value Added (1982 \$, millions)

\begin{tabular}{lrrr} 
& 1977 & 1987 & Change* $^{*}$ \\
\hline All & 934 & 1151 & 2.33 \\
Continuers & 714 & 911 & 2.77 \\
Entrants & & 240 & \\
Exiters & 220 & & \\
\hline
\end{tabular}

- Average Growth over 10 years, not at an annual rate 
Table A.2: Summary Statistics, by Quadrant, 1977-1987, excl Computers

\begin{tabular}{lrrrrr} 
& All Plants & $\Delta \Pi>0$ & $\Delta \Pi>0$ & $\Delta \Pi<0$ & $\Delta \Pi<0$ \\
& & $\Delta L>0$ & $\Delta L<0$ & $\Delta L<0$ & $\Delta L>0$ \\
\hline Estab. & 139985 & 44321.0 & 36049.0 & 19277.0 & 40338.0 \\
pct. & 1.00 & 31.66 & 25.75 & 13.77 & 28.82 \\
Empl. pct. 77 & 1.00 & 23.85 & 44.57 & 18.97 & 12.61 \\
Empl. pct. 87 & 1.00 & 38.18 & 28.16 & 12.04 & 21.61 \\
Empl. Growth & -0.09 & 5.86 & -3.74 & -3.71 & 6.98 \\
VA pct. 77 & 1.00 & 20.19 & 40.42 & 23.44 & 15.95 \\
VA pct. 87 & 1.00 & 41.39 & 36.98 & 7.99 & 13.64 \\
VA Growth & 2.77 & 16.18 & 1.69 & -5.64 & 0.92 \\
Labor Prod. Growth & 2.89 & 6.51 & 8.67 & -3.08 & -3.57 \\
productivity & 3.82 & 6.92 & 9.21 & -3.36 & -3.22 \\
empl. share & 0.02 & -0.30 & 0.28 & 0.23 & 0.03 \\
cross term & -0.95 & -0.11 & -0.83 & 0.06 & -0.38 \\
Contribution to Labor Prod. Growth & & & & \\
by quadrant & 2.89 & 1.88 & 2.37 & -0.62 & -0.74 \\
productivity & & 1.31 & 3.50 & -0.72 & -0.57 \\
empl. share & & -0.22 & 0.15 & -0.16 & 0.24 \\
cross term & & 0.79 & -1.29 & 0.26 & -0.41 \\
\hline
\end{tabular}


Table A.3: Summary Statistics, by Industry, excl Computers

\begin{tabular}{|c|c|c|c|c|c|}
\hline Industry & $\Delta \Pi^{1}$ & Quad I & Quad II & Quad III & Quad IV \\
\hline All Plants & 2.8927 & 30.98 & 36.40 & 15.52 & 17.09 \\
\hline & & \multicolumn{4}{|c|}{ Deviations from above distribution } \\
\hline 20 & 0.4076 & 2.33 & -3.86 & -3.50 & 5.04 \\
\hline 21 & 0.0089 & 1.66 & -6.21 & 18.15 & -13.60 \\
\hline 22 & 0.1217 & 2.24 & 9.74 & .5 .22 & -6.76 \\
\hline 23 & 0.1280 & 1.15 & 3.78 & $\cdot 2.16$ & -2.77 \\
\hline 24 & 0.0617 & 2.64 & -1.42 & -2.06 & 0.85 \\
\hline 25 & 0.0166 & 5.45 & -8.06 & -1.78 & 4.39 \\
\hline 26 & 0.1516 & 0.55 & 2.17 & -2.25 & .0 .46 \\
\hline 27 & 0.0388 & 3.24 & -13.92 & -6.14 & 16.82 \\
\hline 28 & 0.3781 & -5.35 & 8.10 & -2.42 & -0.33 \\
\hline 29 & 0.2600 & -6.93 & 20.25 & -7.39 & .5 .93 \\
\hline 30 & 0.1297 & 7.95 & 0.21 & -4.69 & -3.47 \\
\hline 31 & 0.0158 & -9.43 & 7.33 & 5.48 & -3.38 \\
\hline 32 & 0.0519 & -5.05 & 1.52 & 2.88 & 0.65 \\
\hline 33 & 0.1252 & -15.32 & 21.78 & 3.01 & -9.47 \\
\hline 34 & 0.1538 & -2.80 & 3.05 & 1.51 & -1.75 \\
\hline 35 & 0.0577 & -9.54 & 0.35 & 9.99 & -0.79 \\
\hline 36 & 0.4029 & 12.29 & -5.11 & -2.47 & -4.71 \\
\hline 37 & 0.2191 & 1.79 & -9.82 & 5.02 & 3.01 \\
\hline 38 & 0.1366 & -1.98 & 7.55 & -2.67 & -2.90 \\
\hline 39 & 0.0271 & -2.39 & 0.21 & -0.44 & 2.62 \\
\hline
\end{tabular}

I: $\Delta \Pi>0, \Delta \mathrm{L}>0 ; \quad$ II: $\Delta \Pi>0, \Delta \mathrm{L}<0$; III: $\Delta \mathrm{II}<0, \Delta \mathrm{L}<0$; IV: $\Delta \mathrm{II}<0, \Delta \mathrm{L}>0$

${ }^{1}$ Contributions to labor productivity growth

2 Percent of total employment in each Quadrant 
Table A.4: Summary Statistics, by Region, excl Computers

\begin{tabular}{|c|c|c|c|c|c|}
\hline Region & $\Delta \Pi^{1}$ & Quad I & Quad II & Quad III & Quad IV 2 \\
\hline \multirow[t]{2}{*}{ All Plants } & 2.8927 & 30.98 & 36.40 & 15.52 & 17.09 \\
\hline & & \multicolumn{4}{|c|}{ Deviations from above distribution } \\
\hline New England & 0.1810 & 5.64 & .1 .66 & -2.50 & -1.48 \\
\hline Mid Atlantic & 0.4194 & -2.75 & 2.2 .3 & 0.28 & 0.24 \\
\hline E.N. Central & 0.5550 & -7.73 & 5.01 & 5.34 & -2.62 \\
\hline W.N. Central & 0.2030 & 1.54 & .3 .14 & -1.75 & 3.35 \\
\hline S. Atlantic & 0.4841 & 5.24 & -0.78 & -3.67 & -0.79 \\
\hline E.S. Central & 0.2269 & -0.03 & 3.67 & -0.55 & -3.09 \\
\hline W.S. Central & 0.3896 & -0.89 & -1.31 & 1.11 & 1.09 \\
\hline Mountain & 0.0903 & 6.58 & -6.34 & -3.09 & 2.84 \\
\hline Pacific & 0.3432 & 8.47 & -10.41 & -4.20 & 6.14 \\
\hline \multicolumn{5}{|c|}{$\begin{array}{lr}\text { I: } \Delta \Pi>0, \Delta \mathrm{L}>0 ; & \text { II: } \Delta \Pi>0, \Delta \mathrm{L}<0 ; \\
\text { III: } \Delta \Pi<0, \Delta \mathrm{L}<0 ; & \text { IV: } \Delta \Pi<0, \Delta \mathrm{L}>0 \\
\text { I Contributions to labor productivity growth }\end{array}$} & \\
\hline
\end{tabular}

Table A.5: Summary Statistics, by Size, excl Computers

\begin{tabular}{lr|rrrr} 
Size $^{1}$ & $\Delta \Pi^{2}$ & Quad I & Quad II & Quad III & Quad IV $^{3}$ \\
\hline All Plants & 2.8927 & 30.98 & 36.40 & 15.52 & 17.09 \\
& & \multicolumn{3}{|c}{ Deviations from } & above distribution \\
$1-19$ & 0.0276 & 0.19 & -12.73 & -1.53 & 14.07 \\
$20-49$ & 0.1091 & 4.14 & -9.33 & -1.99 & 7.18 \\
$50-99$ & 0.2054 & 4.44 & -7.45 & -2.46 & 5.47 \\
$100-249$ & 0.4461 & 1.86 & -3.33 & -1.13 & 2.60 \\
$250-499$ & 0.4779 & 0.27 & -0.52 & 0.60 & -0.35 \\
$500-999$ & 0.5748 & -1.96 & 4.15 & 0.93 & -3.13 \\
$1000-2499$ & 0.4571 & -5.31 & 8.62 & 2.39 & -5.70 \\
$2500-4999$ & 0.3175 & -6.33 & 12.88 & 1.08 & -7.63 \\
$5000+$ & 0.2772 & 3.32 & 0.42 & 0.53 & -4.27 \\
\hline
\end{tabular}

I: $\Delta \Pi>0, \Delta \mathrm{L}>0 ; \quad$ II: $\Delta \Pi>0, \Delta \mathrm{L}<0$;

III: $\Delta \mathrm{II}<0, \Delta \mathrm{L}<0 ; \quad$ IV: $\Delta \mathrm{II}<0, \Delta \mathrm{L}>0$

1 A verage of 1977 and 1987 employment, in thousands.

2 Contributions to labor productivity grow'th

${ }^{3}$ Percent of total employment in each Quadrant 
Table A.6: Sumnary Statistics, by Initial Wage, excl Computers

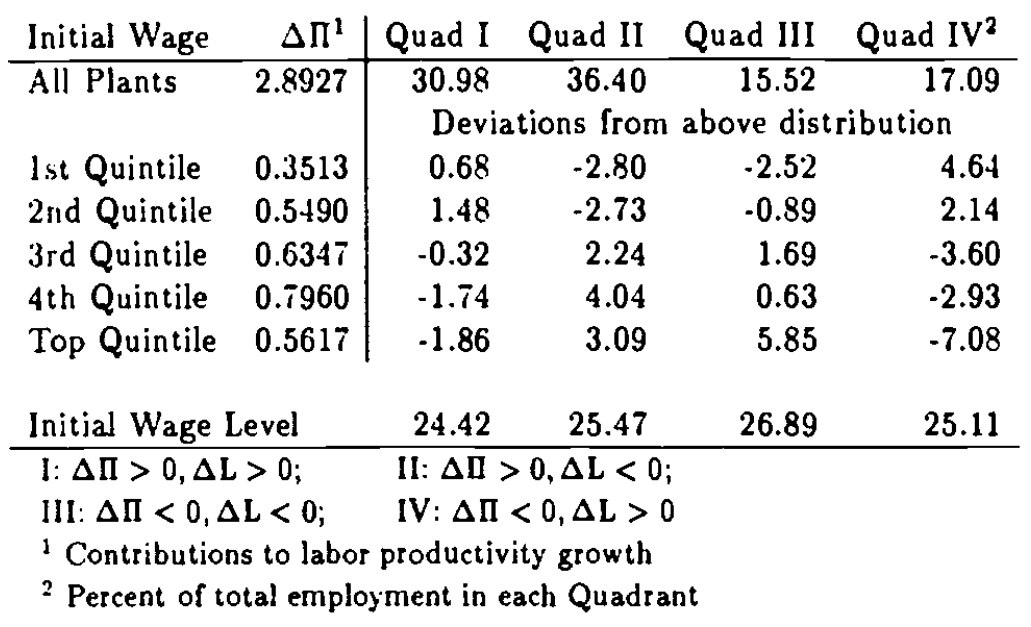

Table A.7: Summary Statistics, by Wage Change, excl Computers

\begin{tabular}{lr|rrrr} 
Wage Change & $\Delta \Pi^{1}$ & Quad I & Quad II & Quad III & Quad IV \\
\hline All Plants & 2.8927 & 30.98 & 36.40 & 15.52 & 17.09 \\
& & \multicolumn{4}{c}{ Deviations from } \\
& & above distribution \\
1st Quintile & -0.0763 & -8.07 & -12.21 & 5.10 & 15.18 \\
2nd Quintile & 0.4343 & -0.91 & -2.26 & 2.80 & 0.37 \\
3rd Quintile & 0.7189 & 4.77 & -0.69 & -0.82 & -3.26 \\
4th Quintile & 0.7001 & 0.45 & 5.05 & -1.24 & -4.26 \\
Top Quintile & 1.1157 & 3.77 & 10.17 & -5.85 & -8.09 \\
Mean Wage Change & 0.68 & 1.87 & -0.27 & -0.80 \\
\hline I: $\Delta \Pi>0, \Delta \mathrm{L}>0 ;$ & II: $\Delta \Pi>0, \Delta \mathrm{L}<0 ;$ \\
III: $\Delta \Pi<0, \Delta \mathrm{L}<0 ;$ & IV: $\Delta \Pi<0, \Delta \mathrm{L}>0$ \\
I Contributions to labor productivity growth \\
2 Percent of total employment in each Quadrant
\end{tabular}


Table A.8: Percent of Variance Explained by Plant, Categories, excl Computers

\begin{tabular}{lrrrrrr} 
Dummy & $\Delta \Pi$ & $\Delta \mathrm{L}$ & $\mathrm{Q}$ I & $\mathrm{Q}$ II & $\mathrm{Q}$ III & Q IV \\
\hline 2-digit Ind. & 3.4 & 1.8 & 2.0 & 2.9 & 1.6 & 2.4 \\
3-digit Ind. & 8.5 & 3.1 & 8.6 & 8.1 & 5.6 & 5.8 \\
4-digit Ind. & 11.8 & 4.3 & 12.6 & 11.5 & 9.6 & 9.9 \\
Size & 1.5 & 0.8 & 0.5 & 1.9 & 0.2 & 2.0 \\
Region & 0.1 & 0.3 & 1.5 & 1.0 & 0.9 & 0.6 \\
Ownership & 0.8 & 2.1 & 0.7 & 1.8 & 0.3 & 1.6 \\
Initial Wage & 2.0 & 0.9 & 0.1 & 0.4 & 0.3 & 1.1 \\
Interaction & 14.7 & 11.7 & 26.6 & 28.3 & 22.8 & 24.5 \\
\hline
\end{tabular}

- Includes 2-dig industry, region, size, type and wage dummies 